\title{
KIT and Melanoma: Biological Insights and Clinical Implications
}

\author{
Duc (Daniel) M. Pham ${ }^{1}$, Samantha Guhan², and Hensin Tsao ${ }^{2,3}$ \\ ${ }^{1}$ Department of Biological Sciences, Korea Advanced Institute of Science and Technology, Daejeon, Korea; \\ ${ }^{2}$ Harvard Medical School, Boston, MA, USA; \\ ${ }^{3}$ Department of Dermatology, Wellman Center for Photomedicine, Massachusetts General Hospital, Harvard Medical School, Boston, MA, USA.
}

\begin{abstract}
Melanoma, originating from epidermal melanocytes, is a heterogeneous disease that has the highest mortality rate among all types of skin cancers. Numerous studies have revealed the cause of this cancer as related to various somatic driver mutations, including alterations in KIT-a proto-oncogene encoding for a transmembrane receptor tyrosine kinase. Although accounting for only $3 \%$ of all melanomas, mutations in c-KIT are mostly derived from acral, mucosal, and chronically sun-damaged melanomas. As an important factor for cell differentiation, proliferation, and survival, inhibition of c-KIT has been exploited for clinical trials in advanced melanoma. Here, apart from the molecular background of c-KIT and its cellular functions, we will review the wide distribution of alterations in KIT with a catalogue of more than 40 mutations reported in various articles and case studies. Additionally, we will summarize the association of KIT mutations with clinicopathologic features (age, sex, melanoma subtypes, anatomic location, etc.), and the differences of mutation rate among subgroups. Finally, several therapeutic trials of c-KIT inhibitors, including imatinib, dasatinib, nilotinib, and sunitinib, will be analyzed for their success rates and limitations in advanced melanoma treatment. These not only emphasize c-KIT as an attractive target for personalized melanoma therapy but also propose the requirement for additional investigational studies to develop novel therapeutic trials co-targeting c-KIT and other cytokines such as members of signaling pathways and immune systems.
\end{abstract}

Key Words: c-KIT protein, melanoma, mutation, therapeutics, clinical trial

\section{OVERVIEW OF c-KIT AND ITS RTKs FAMILY}

c-KIT or CD117 is a member of class III transmembrane receptor tyrosine kinases (RTKs) along with platelet-derived growth factor receptors (PDGFRs), fms like tyrosine kinase 3 (FLT3)/ $\mathrm{CD} 135$, and macrophage colony stimulating factor receptors (M-CSFRs). It was discovered in 1987 as a cellular homologue of viral oncogene $v$-kit, which was isolated from a feline retro-

\footnotetext{
Received: June 10, 2020 Accepted: June 11, 2020

Corresponding author: Hensin Tsao, MD, PhD, Department of Dermatology, Massachusetts General Hospital, Edwards 211, 50 Blossom Street, Boston, MA 02114, USA.

Tel: 1-617-726-9569, Fax: 1-617-726-1206,E-mail: htsao@mgh.harvard.edu

-The authors have no potential conflicts of interest to disclose.

(C) Copyright: Yonsei University College of Medicine 2020

This is an Open Access article distributed under the terms of the Creative Commons Attribution Non-Commercial License (https://creativecommons.org/licenses/ by-nc/4.0) which permits unrestricted non-commercial use, distribution, and reproduction in any medium, provided the original work is properly cited.
}

virus. ${ }^{1,2}$ A variety of cell types were identified to express c-KIT including hematopoietic cells, germ cells, gastrointestinal (GI) tract Cajal cells, melanoma cells, B cell progenitors, and mast cells.

Wild-type c-KIT protein contains 976 amino acids (aa) divided into three main regions including an extracellular ligand-binding domain with 519 aa, a hydrophobic transmembrane domain with 23 aa, and an intracellular tail (Fig. 1). 3,4 The extracellular domain consists of five immunoglobulin-like domains D1-D5, in which D1-D3 is responsible for stem cell factor (SCF) binding while D4-D5 contains motif for receptor dimerization. The 433 aa cytoplasmic region includes a juxtamembrane domain and a tyrosine kinase domain with an insertion of approximately 80 residues. Most of phosphorylation sites on c-KIT are located at the juxta-membrane region, the kinase insertion domain, and the C-terminal tail. Human c-KIT is encoded by a proto-oncogene located on the chromosome 4 at position of q11-12. ${ }^{5}$ This $90 \mathrm{~kb}$ gene is transcribed and translated into a core protein of $110 \mathrm{kDa}$, which is subsequently heterogeneously $\mathrm{N}$-linked glycosylated, mainly in the extra- 


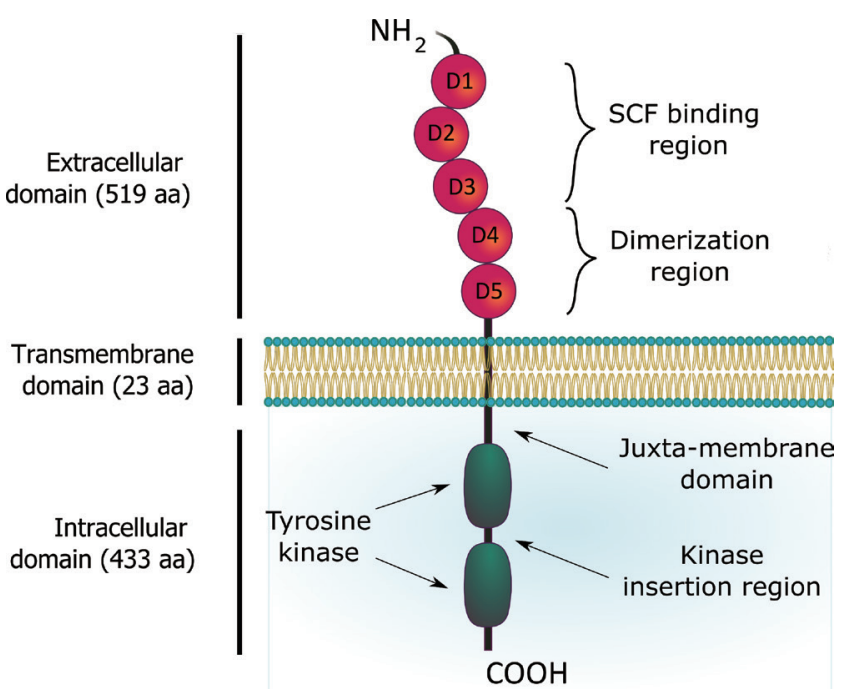

Fig. 1. Structure of c-KIT receptor tyrosine kinase.

cellular domain closest to the plasma membrane, before maturing to a size of $145-160 \mathrm{kDa}^{2,6} \mathrm{c}$-KIT has four isoforms generated by alternative splicing mechanism..$^{7-9}$ The first two isoforms differ in the presence of a glycine-asparagine-asparagine-lysine (GNNK) tetra-peptide adjacent to the extracellular transmembrane domain. The other two relate to the presence or absence of a serine amino acid at position 715 (Ser715) in the kinase insertion region.

The ligand SCF of c-KIT is a hematopoietic cytokine, which signals to maintain survival of hematopoietic cells as well as to promote cell proliferation, differentiation and regulation of growth and development. ${ }^{10}$ Upon binding to D1-D3 region of c-KIT, a homodimer of SCF induces a conformational change that enables a homotypic interaction between D4-D5 regions of two adjacent c-KIT molecules. ${ }^{11,12}$ This dimerization allows a trans-phosphorylation of tyrosine residues in the intracellular region of each c-KIT monomer by the other, leading to signal transduction through plasma membrane. Many mutations in c-KIT have been found to perturb these characteristics. For example, a mutation in $\mathrm{D} 4$ at key residues disrupts the transmembrane regions of each monomer, thereby blocking the subsequent trans-phosphorylation of tyrosine kinase domains. ${ }^{13}$ However, this kind of mutation dramatically reduces tyrosine phosphorylation but does not influence the dimerization. A comprehensive summary of KIT mutations and their respective clinical implications will be further discussed in detail later.

\section{Downstream signaling pathways of c-KIT}

Many studies have been done on various cell lines to describe different downstream signaling cascades of c-KIT, including mitogen-activated protein kinase/extracellular signal-regulated kinase (MAPK/ERK) pathway, PI3K/AKT pathway, Src family kinases pathway, phospholipases PLC- $\gamma$ pathway, and JAK/ STAT pathway. ${ }^{14-18}$ These signaling pathways can be activated independently or concomitantly by c-KIT and they are inte-

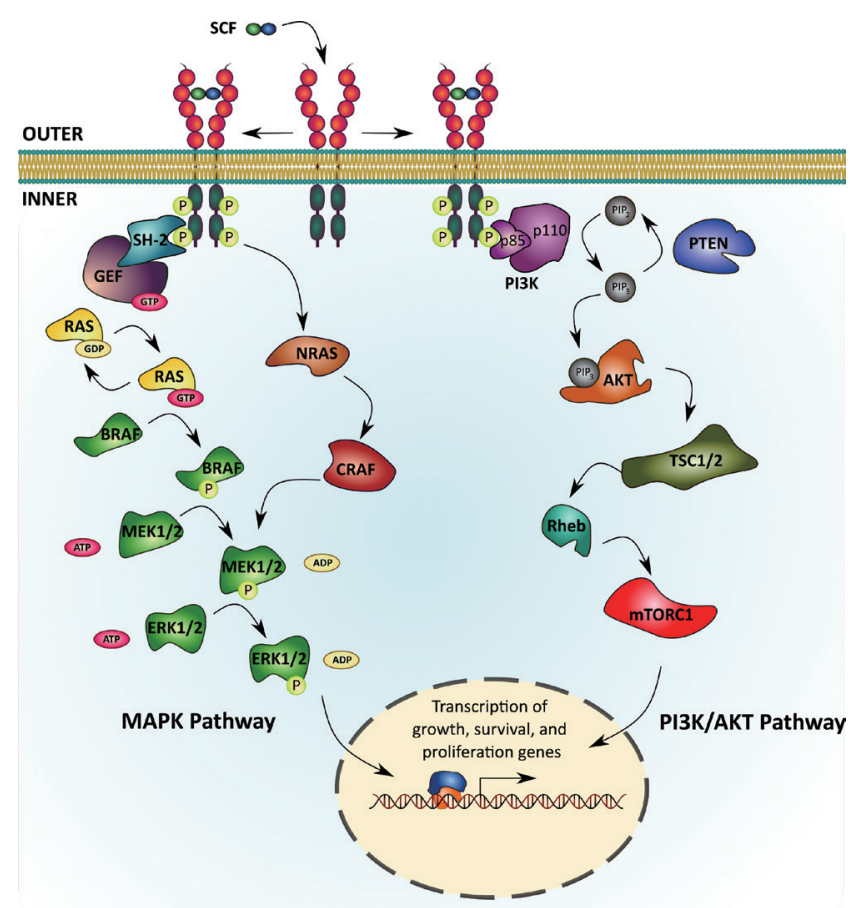

Fig. 2. c-KIT mediated signaling pathways.

grated into a signaling circuit. Since different pathways relate to different cell types as well as cancer types, we will review in detail only pathways that are mostly well-known and researched on in c-KIT derived melanoma, which are MAPK/ ERK pathway and PI3K/AKT pathway (Fig. 2).

\section{MAPK/ERK pathway}

Through trans-phosphorylation by SCF binding, c-KIT is activated and recruits adaptor proteins containing a Src homology 2 (SH-2) domain. This $\mathrm{SH}-2$ protein will then associate with a guanine nucleotide exchange factor (GEF) that exchanges guanosine triphosphate (GTP) and guanosine diphosphate (GDP). This SH-2/GEF complex activates the G-protein RAS by transferring its GTP. ${ }^{19}$ Activation of RAS leads to the activation of a serine/threonine protein kinase BRAF, which subsequently phosphorylates mitogen-activated protein kinase kinase1/2 (MAP2K1/2 or MEK1/2). MEK1/2, in turn, phosphorylates and activates ERK1/2. Several ERK1/2-activated transcription factors (TFs) induce the expression of genes related to cell proliferation, apoptosis, differentiation, adhesion, and mobility. ${ }^{20,21}$

\section{PI3K/AKT pathway}

PI3K/AKT pathway is responsible for cell survival and regulation of apoptosis. This signaling pathway can be activated via two mechanisms: either directly through interaction with c-KIT at position Tyr721 or indirectly through scaffold protein Gab2 and adapter protein Grb2. ${ }^{22,23}$ The p85 subunit of PI3K interacts with autophosphorylated c-KIT through its SH2 domain, changes conformation, and associates with the enzymatic p110 subunit to fully activate PI3K. That activation step also recruits 
PI3K to plasma membrane, placing it in close proximity of its lipid substrate, phosphatidylinositol 4,5-biphosphate (PIP2), which converts PIP2 to phosphatidylinositol 3,4,5-triphosphate (PIP3). The PIP3 then activates the pleckstrin homology (PH) domain, which contains proteins such as the serine/threonine kinase AKT.

AKT can activate several downstream proteins such as Bad, Foxo, and nuclear factor kappa-light chain enhancer of activated $B$ cells (NF- $\kappa \mathrm{B}$ ) to interfere with the initiation of apoptosis and promote cell survival. ${ }^{24-27}$ AKT also activates mTORC1 or mTor complex 1 (mTor, Raptor, GßL, PRAS40, and Deptor) through downstream pathway members like TSC1/2 and Rheb. This mTORC1 relates to melanocyte proliferation and migration. ${ }^{28}$ The PI3K/AKT pathway can be inhibited by the phosphatase and tensin homolog (PTEN) gene. The PTEN protein removes one inorganic phosphate group from $\mathrm{PIP}_{3}$ to regenerate $\mathrm{PIP}_{2}$, which prevents the activation of AKT.

\section{KIT interactions with other cytokines}

It is well established that c-KIT interacts with various families of adaptor proteins, which contain multiple interaction domains, including SH2 and $\mathrm{PH}$. Among growth factor receptorbound proteins, c-KIT was shown to interact with Grb7 at Tyr936 position in the downstream signaling of cell migration. ${ }^{29,30}$ Another member in this family, Grb10, was found to interact with c-KIT to facilitate its PI3K-kinase-dependent activation and following association with $\mathrm{AKT} .{ }^{31} \mathrm{CrkL}$, a member of Crk family, has its phosphorylation induced by c-KIT and can interact with the ubiquitin E3 ligase c-Cbl. ${ }^{32}$ Activation of c-KIT can also trigger the binding to its juxta-membrane region of Dokl, an adaptor that can interact with many signaling proteins such as Abl, SHIP, PLC $\gamma 1$, and CrkL. ${ }^{33}$ Another interactor of c-KIT, Lnk, may negatively regulate function of c-KIT as $\ln k^{-/}$ mice had an enhanced hematopoiesis. ${ }^{34}$

Apart from adaptor proteins, c-KIT can interact with and facilitate functions of many different cytokines. For examples, in primary mast cells, SCF-induced activation of c-KIT is required to evoke optimal IL-33-induced cytokine production. ${ }^{35} \mathrm{c}$-KIT can also affect erythropoiesis as it can replace erythropoietin (Epo) to activate its receptor (Epo-R) by tyrosine phosphorylation and induce maturation of progenitors. ${ }^{36}$ Similar with the interaction between c-KIT and Epo-R, the interaction with IL-7 of c-KIT can indirectly stimulate Jak-Stat pathway in T-lymphoid cells under the absence of Stat 5 activation. ${ }^{37}$ In myeloid cell line, interestingly, members of the transmembrane 4 superfamily (TM4SF), including CD9, CD63, and CD81, show their physical association and serve as negative modulators of c-KIT, thus, regulating its sensitivity to Steel factor (SLF) in hematopoietic progenitors. ${ }^{38}$

\section{KIT mutations in melanoma}

Dysregulation of c-KIT can affect cell proliferation, tumor growth, and metastasis in various cancer types such as gastrointestinal stromal tumors (GIST), leukemia (the first tumor found linked to KIT mutation), lung cancer, acute myeloid leukemia, and melanoma. ${ }^{3,7,39,40}$ In fact, KIT mutations (mainly in-frame deletions of exon 11) are found in $80 \%$ of GIST tumors. ${ }^{41,42}$ Apart from gene amplifications, KIT mutations in melanoma are almost all missense substitutions and widely distributed (Fig. 3). Table 1 shows a catalogue of 47 recorded KIT mutations based on data collected from a pooled analysis of 1635 patients samples from 12 recent melanoma genomics studies using cBioPortal (www.cbioportal.org) and several separate studies. ${ }^{43-54}$ KIT mutations are identified in 3\% of all melanomas and more specifically in $36 \%$ of acral melanomas, $39 \%$ of mucosal melanomas, and $28 \%$ of melanomas on chronically sun-damaged (CSD) skin but none in melanomas on skin without CSD or non-CSD (NCSD). ${ }^{46}$ About $70 \%$ of KIT mutations in melanoma are localized to exon 11, most often a lysine-toproline mutation at codon 576 (L576P), and to exon 13, most often a methionine-to-glutamic acid mutation at codon 642 (K642E). L576P affects the juxta-membrane domain and K642E affects a kinase domain. Both mutations lead to constitutive activation of c-KIT tyrosine kinase activity and subsequent induction of both MAPK and PI3K/AKT pathways. ${ }^{55}$ Interestingly, mutations in KIT almost never occur in conjunction with BRAF (V600E) and NRAS (G12/Q61) mutations thereby suggesting an epistatic relationship. ${ }^{56}$ Melanomas without these recurrent alterations in $B R A F$ and NRAS have a significant enrichment for either KIT mutations or alterations in NF1, a downstream modulator in c-KIT/MITF signaling axis. ${ }^{48}$

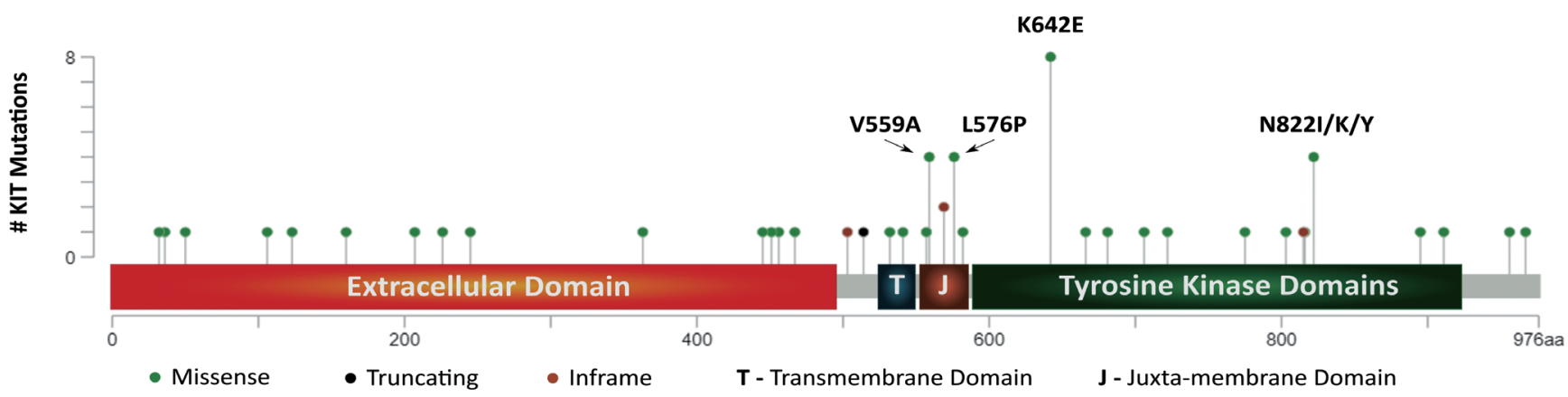

Fig. 3. Wide distribution of KIT genetic alterations in melanoma (from cBioPortal). ${ }^{43-54}$ 
Duc (Daniel) M. Pham, et al.

Table 1. Catalogue of KITMutations in Melanomas

\begin{tabular}{|c|c|c|c|c|c|c|c|}
\hline No & KIT mutation & Mutation type & $\begin{array}{l}\text { Variation } \\
\text { type }\end{array}$ & $\begin{array}{c}\text { Copy } \\
\text { number }\end{array}$ & $\begin{array}{c}\text { Exon } \\
\text { location }\end{array}$ & Corresponding region & Cancer type \\
\hline 1 & G32V & Missense & $\mathrm{G} \rightarrow \mathrm{T}$ & ShallowDel & 2 & Extracellular domain & Cutaneous melanoma \\
\hline 2 & P360 & Missense & $C \rightarrow A$ & Gain & 2 & Extracellular domain & Cutaneous melanoma \\
\hline 3 & V50L & Missense & $G \rightarrow C$ & - & 2 & Extracellular domain & Desmoplastic melanoma \\
\hline 4 & S106F & Missense & $\mathrm{C} \rightarrow \mathrm{T}$ & Diploid & 2 & Extracellular domain & Cutaneous melanoma \\
\hline 5 & S123F & Missense & $C \rightarrow T$ & Diploid & 3 & Extracellular domain & Cutaneous melanoma \\
\hline 6 & L160V & Missense & $\mathrm{T} \rightarrow \mathrm{G}$ & - & 3 & Extracellular domain & Cutaneous melanoma \\
\hline 7 & A207S & Missense & $\mathrm{G} \rightarrow \mathrm{T}$ & Diploid & 3 & Extracellular domain & Cutaneous melanoma \\
\hline 8 & G226W & Missense & $\mathrm{G} \rightarrow \mathrm{T}$ & Gain & 4 & Extracellular domain & Cutaneous melanoma \\
\hline 9 & T245M & Missense & $\mathrm{C} \rightarrow \mathrm{T}$ & Diploid & 4 & Extracellular domain & Cutaneous melanoma \\
\hline 10 & P363S & Missense & $C \rightarrow T$ & Diploid & 6 & Extracellular domain & Cutaneous melanoma \\
\hline 11 & G445E & Missense & $\mathrm{G} \rightarrow \mathrm{A}$ & - & 8 & Extracellular dimerization motif & Cutaneous melanoma \\
\hline 12 & S451C & Missense & $\mathrm{C} \rightarrow \mathrm{G}$ & Gain & 9 & Extracellular dimerization motif & Cutaneous melanoma \\
\hline 13 & P4560 & Missense & $C \rightarrow A$ & - & 9 & Extracellular dimerization motif & Cutaneous melanoma \\
\hline 14 & P4670 & Missense & $C \rightarrow A$ & Diploid & 9 & Extracellular dimerization motif & Cutaneous melanoma \\
\hline 15 & N463S & Missense & - & - & 9 & Extracellular dimerization motif & Mucosal melanoma \\
\hline 16 & Y503del_insFAH & In-frame Ins & $-\rightarrow$ TTGCCC & Amp & 9 & Extracellular dimerization motif & Cutaneous melanoma \\
\hline 17 & V5321 & Missense & $\mathrm{G} \rightarrow \mathrm{A}$ & Diploid & 10 & Transmembrane domain & Melanoma \\
\hline 18 & M541L & Missense & $A \rightarrow C$ & ShallowDel & 10 & Transmembrane domain & Melanoma of unknown primary \\
\hline 19 & W557R & Missense & $\mathrm{T} \rightarrow \mathrm{A} / \mathrm{C}$ & Amp & 11 & Juxta-membrane domain & Acral, mucosal, cutaneous melanoma \\
\hline 20 & V559A & Missense & $\mathrm{T} \rightarrow \mathrm{C}$ & $\begin{array}{l}\text { Diploid/ } \\
\text { ShallowDel }\end{array}$ & 11 & Juxta-membrane domain & Acral, mucosal, cutaneous melanoma \\
\hline 21 & V559D & Missense & $\mathrm{T} \rightarrow \mathrm{A}$ & - & 11 & Juxta-membrane domain & Acral, mucosal melanoma \\
\hline 22 & V569A & Missense & $\mathrm{T} \rightarrow \mathrm{C}$ & - & 11 & Juxta-membrane domain & Cutaneous melanoma \\
\hline 23 & $\mathrm{Y} 570 \mathrm{H}$ & Missense & - & - & 11 & Juxta-membrane domain & CSD melanoma \\
\hline 24 & Y570_L576del & In-frame Del & $\Pi \mathrm{T} \rightarrow-$ & - & 11 & Juxta-membrane domain & Cutaneous melanoma \\
\hline 25 & L576P & Missense & $T \rightarrow C$ & Amp & 11 & Juxta-membrane domain & Acral, mucosal melanoma \\
\hline 26 & W582L & Missense & $\mathrm{G} \rightarrow \mathrm{T}$ & ShallowDel & 11 & Juxta-membrane domain & Cutaneous melanoma \\
\hline 27 & K642E & Missense & $A \rightarrow G$ & $\begin{array}{l}\text { Amp/Gain/ } \\
\text { Diploid }\end{array}$ & 13 & TKI domain/ATP-binding pocket & Acral, mucosal, cutaneous melanoma \\
\hline 28 & V654A & Missense & - & - & 13 & TKI domain/ATP-binding pocket & Mucosal melanoma \\
\hline 29 & T666l & Missense & $C \rightarrow T$ & - & 14 & Kinase insertion domain & $\begin{array}{l}\text { Cutaneous melanoma, } \\
\text { lentigo maligna melanoma }\end{array}$ \\
\hline 30 & F681I & Missense & $\mathrm{T} \rightarrow \mathrm{A}$ & - & 14 & Kinase insertion domain & Desmoplastic Melanoma \\
\hline 31 & L706F & Missense & $C \rightarrow T$ & Diploid & 14 & Kinase insertion domain & Cutaneous melanoma \\
\hline 32 & M722I & Missense & $\mathrm{G} \rightarrow \mathrm{T}$ & Diploid & 15 & Kinase insertion domain & Cutaneous melanoma \\
\hline 33 & Q775K & Missense & $C \rightarrow A$ & Diploid & 16 & Kinase domain & Cutaneous melanoma \\
\hline 34 & G803C & Missense & $\mathrm{G} \rightarrow \mathrm{T}$ & Diploid & 17 & Kinase domain & Cutaneous melanoma \\
\hline 35 & R815_D816delinsS & IF del & & Diploid & 17 & Kinase domain & Cutaneous melanoma \\
\hline 36 & D816N & Missense & $\mathrm{G} \rightarrow \mathrm{A}$ & Amp & 17 & Kinase domain & Cutaneous melanoma \\
\hline 37 & D820Y & Missense & - & - & 17 & Kinase domain & Mucosal melanoma \\
\hline 38 & N822I & Missense & $A \rightarrow T$ & Amp & 17 & Kinase domain & Cutaneous melanoma \\
\hline 39 & N822K & Missense & $\mathrm{T} \rightarrow \mathrm{G}$ & Gain & 17 & Kinase domain & Cutaneous melanoma \\
\hline 40 & N822Y & Missense & $A \rightarrow T$ & Amp & 17 & Kinase domain & Cutaneous melanoma \\
\hline 41 & A829P & Missense & - & - & 18 & Kinase domain & Mucosal melanoma \\
\hline 42 & P838L & Missense & - & - & 18 & Kinase domain & Acral melanoma \\
\hline 43 & V8521 & Missense & - & - & 18 & Kinase domain & Mucosal melanoma \\
\hline 44 & A895T & Missense & $\mathrm{G} \rightarrow \mathrm{A}$ & - & 19 & Kinase domain & Cutaneous melanoma \\
\hline 45 & P911L & Missense & $C \rightarrow T$ & - & 20 & Kinase domain & Cutaneous melanoma \\
\hline 46 & R9560 & Missense & $\mathrm{G} \rightarrow \mathrm{A}$ & - & 21 & C-terminal tail & Melanoma \\
\hline 47 & S967F & Missense & $\mathrm{CC} \rightarrow \mathrm{TT}$ & - & 21 & C-terminal tail & Cutaneous melanoma \\
\hline
\end{tabular}

CSD, chronically sun-damaged. 


\section{CLINICAL IMPLICATIONS OF KIT MUTATIONS}

\section{Correlations between clinical features and KIT mutations}

The KIT mutation rate and its association with various clinicopathological features remains controversial as results of different studies are inconsistent. Here, we summarize the data from Gong, et al's 2018 meta-analysis ${ }^{57}$ of the clinical implications of KIT mutations (Table 2). In this analysis, selected studies must satisfy three inclusion criteria: 1) KIT mutations detected in the tissue samples of human melanoma, but not in cell lines, 2) the incidence of KIT mutations according to clinicopathologic parameters was described in detail, and 3) studies were carried out on humans and published in Eng-

Table 2. Associations between KITMutations and Various Clinicopathological Features/Races of Melanomas

\begin{tabular}{|c|c|c|c|c|}
\hline $\begin{array}{l}\text { Clinicopathologic } \\
\text { characteristics }\end{array}$ & OR & $95 \% \mathrm{Cl}$ & $p$ value & $\begin{array}{c}\text { Association } \\
\text { with } K I T \\
\text { mutation }\end{array}$ \\
\hline \multicolumn{5}{|l|}{$\operatorname{Age}(\geq 60 \mathrm{yr})$} \\
\hline Asian & 1.349 & $1.056-1.723$ & 0.017 & Positive \\
\hline White & 0.795 & $0.337-1.879$ & 0.602 & None \\
\hline Overall & 1.296 & $1.025-1.641$ & 0.031 & Positive \\
\hline \multicolumn{5}{|l|}{ Sex } \\
\hline Asian & 1.134 & $0.910-1.412$ & 0.264 & None \\
\hline White & 0.860 & $0.426-1.735$ & 0.674 & None \\
\hline Overall & 1.106 & $0.897-1.364$ & 0.347 & None \\
\hline \multicolumn{5}{|l|}{ Mucosal melanoma } \\
\hline Asian & 1.080 & $0.842-1.386$ & 0.545 & None \\
\hline White & 3.003 & $1.895-4.758$ & $<0.001$ & Positive \\
\hline Overall & 1.363 & $1.094-1.697$ & 0.006 & Positive \\
\hline \multicolumn{5}{|l|}{ Acral melanoma } \\
\hline Asian & 1.361 & 1.087-1.702 & 0.007 & Positive \\
\hline White & 1.435 & $0.901-2.286$ & 0.128 & None \\
\hline Overall & 1.374 & $1.123-1.682$ & 0.002 & Positive \\
\hline \multicolumn{5}{|c|}{ Cutaneous melanoma with NCSD } \\
\hline Asian & 0.613 & $0.424-0.886$ & 0.009 & Negative \\
\hline White & 0.094 & $0.018-0.500$ & 0.006 & Negative \\
\hline Overall & 0.562 & $0.392-0.805$ & 0.002 & Negative \\
\hline \multicolumn{5}{|c|}{ Cutaneous melanoma with CSD } \\
\hline Asian & 1.643 & $0.962-2.806$ & 0.069 & None \\
\hline White & 7.791 & $1.370-44.291$ & 0.021 & Positive \\
\hline Overall & 1.880 & $1.127-3.136$ & 0.016 & Positive \\
\hline $\begin{array}{l}\text { Melanoma on the } \\
\text { extremities }\end{array}$ & 0.294 & $0.105-0.820$ & 0.019 & Negative \\
\hline \multicolumn{5}{|l|}{ Breslow thickness } \\
\hline$>1 \mathrm{~mm}$ & 0.910 & $0.586-1.413$ & 0.674 & None \\
\hline$>4 \mathrm{~mm}$ & 1.177 & $0.928-1.492$ & 0.179 & None \\
\hline Ulceration & 0.968 & $0.772-1.215$ & 0.781 & None \\
\hline
\end{tabular}

CSD, chronically sun-damaged; NCSD, non-CSD; OR, odds ratio; Cl, confidence interval. lish. This study collected data from 497 out of 5224 patients harboring KIT mutations, comprising 360 Asian patients and 137 White patients.

The authors reported that KIT mutations are more commonly found in older patients ( $\geq 60$ years old) [odds ratio $(\mathrm{OR})=$ 1.296, 95\% confidence interval (CI): 1.025-1.641; $p=0.031$ ] and are positively associated with both mucosal melanomas $(\mathrm{OR}=$ 1.363, 95\% CI: 1.094-1.697; $p=0.006)$ and acral melanomas (OR=1.374, 95\% CI: 1.123-1.682; $p=0.002$ ). When stratified by race, KIT was significantly associated with mucosal melanoma in White patients and acral melanoma in Asian patients. Additionally, a negative association was detected between KIT mutations and NCSD melanomas in both populations. However, there was a positive association between KIT mutations and CSD melanomas overall (OR=1.880, 95\% CI: $1.127-$ 3.136; $p=0.016$ ). KIT mutations are usually not found in melanomas that develop on the extremities and not correlated with melanoma on head/neck or trunk. Analyses also showed no significant relationship between KIT mutations and sex, Breslow thickness (either $>1 \mathrm{~mm}$ or $>4 \mathrm{~mm}$ ), histological types, ulceration, mitotic rate, and tumor stages.

Overall, this meta-analysis documented a close association between KIT mutations and older age, acral mucosal subtypes of melanoma, and CSD sites, but did not find an association with histological subtypes or tumor stage. However, the results of this study are limited by the number of published data as well as the wide distribution of KIT mutations in various exons. The clinical implications of KIT mutations are informative clues for developing individualized therapies for patients, which will be reviewed in the next section.

\section{Therapeutic trials of c-KIT inhibitors and success rates in melanomas}

A variety of kinase inhibitors have been developed exploring c-KIT as a therapeutic target in melanoma, but not all drugs have been approved for clinical trials. In this section, we summarize data from 13 studies that reported the success rates of four widely used c-KIT inhibitors in melanoma treatments. Summary of those clinical trials in sample size, objective response rate (ORR), disease control rate (DCR), median progression-free survival (PFS), and median overall survival (OS) is shown in Table 3.

\section{Imatinib}

Imatinib, or imatinib mesylate, which was initially developed as an inhibitor of the BCR-ABL fusion protein and PDGFR, was found to also inhibit c-KIT and considered an effective drug for treatment of patients with GIST. ${ }^{58,59}$ Clinical experience in four single-arm, open-label phase II trials of imatinib ${ }^{44,60-62}$ will be compared. The most recent study among these screened 78 patients for response after continuous treatment with 400 $\mathrm{mg} /$ day imatinib until intolerable toxicities or disease progression occurred. Mutations in patients were widely distrib- 
Table 3. Summary of Clinical Trials of KIT Inhibitors in KIT-Mutation Derived Melanomas

\begin{tabular}{|c|c|c|c|c|c|c|c|}
\hline No. & $\begin{array}{c}\text { KIT } \\
\text { inhibitors } \\
\text { (mg) }\end{array}$ & $\begin{array}{c}\text { No. of } \\
\text { patients }\end{array}$ & $\begin{array}{l}\text { ORR } \\
(\%)\end{array}$ & $\begin{array}{l}\text { DCR } \\
\text { (\%) }\end{array}$ & $\begin{array}{l}\text { Median } \\
\text { PFS } \\
\text { (months) }\end{array}$ & $\begin{array}{l}\text { Median } \\
\text { OS } \\
\text { (months) }\end{array}$ & Study \\
\hline 1 & IMA 400 BID & 25 & 16 & 36 & 2.8 & 10.7 & Carvajal, \\
\hline 2 & $\begin{array}{l}\text { IMA } 400 \\
\text { OD or BID }\end{array}$ & 43 & 23.3 & 53.5 & 3.5 & 12.0 & \\
\hline 3 & $\begin{array}{l}\text { IMA } 400 \\
\text { OD or BID }\end{array}$ & 24 & 29.2 & 50 & 3.7 (TTP) & 12.5 & Hodi, et al. ${ }^{61}$ \\
\hline 4 & IMA 400 QD & 78 & 21.8 & 60.3 & 4.2 & 13.1 & \\
\hline 5 & NIL 400 BID & 9 & 22.2 & 77.8 & 2.5 & - & \\
\hline 6 & NIL 400 BID & 19 & 15.8 & 52.6 & 3.3 (TTP) & 9.1 & Carvajal, et al \\
\hline 7 & NIL 400 BID & 42 & 16.7 & 57.1 & 3.3 & 11.9 & \\
\hline 8 & NIL 400 BID & 42 & 26.2 & 73.8 & 4.2 & 18.0 & \\
\hline 9 & NIL 400 BID & 25 & 16 & 64 & 6.0 & 13.2 & Dely \\
\hline 10 & DAS 70 BID & 36 & 5 & - & 2.0 & 13.8 & \\
\hline 11 & DAS 70 BID & 22 & 18.2 & 50 & 2.1 & 7.5 & Kalinsky, et al. ${ }^{69}$ \\
\hline 12 & SUN 50 QD & 10 & 40 & 50 & - & - & Minor, et al. ${ }^{72}$ \\
\hline 13 & SUN 50 OD & 31 & 13 & 39 & 1.3 (TTP) & 4.3 & Decoster, et al. ${ }^{71}$ \\
\hline
\end{tabular}

ORR, objective response rate; $D C R$, disease control rate; PFS, progressionfree survival; OS, overall survival; BID, twice daily; OD, once daily; IMA, imatinib; NIL, nilotinib; DAS, dasatinib; SUN, sunitinib; TTP, time to progression.

uted in exons $9,11,13,17$, and 18 , with $60.2 \%$ of mutations occurring in exon 11 or 13. L576P and K642E accounted for $24.3 \%$ of all mutations. The median PFS in the evaluable cohort was 4.2 months (95\% CI: 1.9-6.4 months), and median OS was 13.1 months (95\% CI: 9.6-16.7 months). A range of durability was recorded with 17 partial response (PR) patients, 30 stable disease (SD) patients, and 29 patients showing progressive disease (PD). Differences were found between patients with KIT mutations. Patients with KIT mutations in exon 11 or 13 had ORR of $24.4 \%$ and DCR of $66.7 \%$ while those for the group of other alterations had the rate of $19.4 \%$ and $54.8 \%$ respectively. This study observed generally mild to moderate adverse events (AEs), including edema (50\%), rash (18\%), fatigue ( $9 \%)$, anorexia (7\%), nausea (5\%), and neutropenia ( $2 \%)$. The additional three studies showed consistent results. These studies started with high dose of imatinib (400 mg twice a day), which was commonly associated with grades $3-4$ AEs such as lymphopenia, anemia, erythema multiforme, and vomiting. Among four studies, complete responses (CRs) were only observed in the earliest study of Carvajal group with two patients durable for 95 and 94 weeks. Both of them had the exon 11 L576P mutation as well as amplification of KIT.44

\section{Nilotinib}

Nilotinib is another small kinase inhibitor with comparable or greater potency than imatinib in targeting KIT mutations. ${ }^{63}$ Five studies were conducted using this drug, in which all patients received orally nilotinib $400 \mathrm{mg}$ twice a day. ${ }^{56,64-67}$ The most recent study was a phase II clinical trial conducted by the
French Skin Cancer Network on 25 patients. ${ }^{65}$ At 6 months after nilotinib initiation, only four patients were responsive to nilotinib (ORR: 16\%, 90\% CI: 5.6-33.0\%), including one CR patient and three PR patients. Out of the other 21 patients, six experienced progression and 15 died with an estimated PFS of 6.0 months and a median OS of 13.2 months (95\% CI: 5.6-19.9 months). Of note, patients with CR or PR had mutations in exon 11 or 13 with overall response rate of $26 \%$, median PFS of 6 months (95\% CI: 3-46.8), and median OS of 14.4 months (95\% CI: 9.97-not reached). Among patients, $56 \%$ experienced grade 3 drug-related AEs such as fatigue, rash, increased aspartate transaminase/alanine transaminase or cholestasis, and nausea. The author also observed reduced phosphorylated STAT3 in nilotinib treated KIT-mutated cell lines, suggesting that the JAK/STAT pathway can be downregulated by c-KIT inhibition and thus, associated with tumor response. However, additional mechanistic studies and molecular profiling are required, as nilotinib also targets PDGFR and ABL, which can both signal through STAT3. Other studies were conducted in patients with or without prior targeted KIT therapy. In the study of 19 patients, patients with L576P mutation showed a $25 \%$ ORR and $50 \%$ DCR while those for K642E mutation were $25 \%$ and $75 \%$ respectively. ${ }^{56}$ Of note, this study recorded two patients with reduction in size of brain metastases after nilotinib treatment by magnetic resonance imaging scanning.

\section{Dasatinib}

Dasatinib is also a c-KIT inhibitor, which also targets Src family kinases (c-Src, YES, LCK, and FYN), BCR-ABL, PDGFR- $\beta$, and EPHA2 ${ }^{68}$ Two studies of 36 and 22 evaluable patients respectively were conducted to assess clinical efficacy of dasatinib in KIT-mutated melanoma treatment. ${ }^{69,70}$ Both studies treated patients with various starting doses of dasatinib but eventually fixed at $70 \mathrm{mg}$ twice a day due to toxicity. No CR case was observed in either study. In the first study, only two patients showed PR lasting 64 and 24 weeks, causing an ORR of $5 \%{ }^{70}$ Meanwhile, in the second study, four PRs and seven SDs were observed. Common grade 3 AEs were recorded, including fatigue (13\%), dyspnea (12\%), nausea (11\%), anemia (7\%), pleural effusion (5\%), etc.

\section{Sunitinib}

Sunitinib, which targets both c-KIT and vascular endothelial growth factor receptors (VEGFRs), is also approved for treating melanoma. Sunitinib was examined in two studies of 10 and 31 evaluable patients harboring KIT mutations in 2012 and 2015, respectively. ${ }^{71,72}$ Both of studies started with sunitinib 50 mg daily before reducing to 37.5 and $25 \mathrm{mg}$ per day. One CR with 15 months of durability was observed in the 2012 study. However, the 2015 study recorded no CR but observed 13\% PR and 26\% SD, which accounted for a DCR of $39 \%$. The median PFS and median OS for the overall population in this study were 1.3 months (95\% CI: $1.2-1.4$ ) and 4.3 months (95\% CI: 
1.0-7.6), respectively. Most commonly recorded grade 3-4 AEs were asthenia (28\%), thrombocytopenia (15\%), anorexia $(10 \%)$, and neutropenia (15\%).

Several other kinase inhibitors targeting c-KIT were also clinically tested and recorded in case reports. For example, a patient with primary esophageal melanoma harboring KIT mutation in exon 11 showed significant response when being treated with oral masitinib. ${ }^{73}$ Masitinib treatment caused dysphagia and odynophagia disappeared within 1 week and reduced size of brain metastatic lesions and visceral lesions in the following month. Another example is a 79-year-old man at stage IV M1b metastatic anal mucosal melanoma showing CR upon sorafenib therapy. ${ }^{74}$

\section{Epigenetic regulation of $K I T$}

Several up/down regulations of KIT expression are caused by epigenetic changes, which includes DNA methylation and histone modifications. For example, in cardiac progenitor cells, $K I T$ is upregulated via action of stromal cell-derived factor- $1 \alpha$ (SDF-1 $\alpha$ ). SDF-1 $\alpha$, combined with CXCR4, inhibits expression and global activity of DNA methyltransferase (DNMT), which then leads to demethylation of c-KIT gene. ${ }^{75}$ In KIT-mutated mast cells, histone deacetylase inhibitors (HDACi) can decrease KIT mRNA levels, total c-KIT protein as well as cell surface c-KIT, followed later by major mast cell apoptosis. ${ }^{76}$ Some breast cancer cell lines lack the c-KIT expression due to hypermethylation of KIT promoter and treating these cell lines with methyltransferase inhibitor such as $5 \mathrm{Aza}-2 \mathrm{dC}$ can boost the level of KIT mRNA. ${ }^{77}$ KIT methylation is also recorded in squamous cell carcinoma of uterine cervix that overexpress cKIT. $^{78,79}$ The increased methylation of CpG islands in these skin cancer cells might interfere with the binding of CTCF repressor with KIT promoter. In GIST, a repressive complex named PRC [polycomb group (PcG) repressive complex] can reversibly suppress KIT expression via various histone modifications such as H3K27me3 and H2AK119ub1. ${ }^{80}$ In cutaneous melanoma, intriguingly, the presence of SCF leads to reduced KIT expression and increased methylation density at the KIT promoter. $^{81}$ However, this epigenetic change shows no significant correlations with common genetic drivers such as BRAF, NRAS, and PTEN. This suggests that KIT may have a tumor-suppressive function in cutaneous melanoma. ${ }^{82-84}$ Supporting this tumorsuppressing role of KIT in melanoma, the hypermethylation of $K I T$ is also associated with a lower OS rate, even when $B R A F$ $(V 600 E)$ is included for the survival risk prediction. ${ }^{85}$ Additionally, KIT is also found to be inhibited by microRNAs, including miR-221 and miR-222, which leads to differentiation blockade of the melanoma cells and subsequent proliferation. ${ }^{86}$ However, these microRNAs are repressed by a TF called promyelocytic leukemia zinc finger (PLZF); therefore, the silencing of PLZF can be a driver of cutaneous melanoma.

On the other hand, considering KIT as an oncogene, the epigenetic regulation of KIT is related to enhancers, those are dif- ferentially methylated regions (eDMRs) as melanomas progress from normal to primary tumors and then to metastases. ${ }^{87}$ Bell, et al. ${ }^{87}$ showed that the methylation patterns of eDMRs not only contributes to melanoma progression by overexpressing KIT but also distinguishes patient survival rates.

\section{CONCLUSION}

Overall, based on data from various studies and case reports, we created a catalogue of KIT mutations, though not sufficient, and their mostly associated melanoma subtypes. An understanding of mutational classes in melanoma will facilitate appropriate personalized treatments. Additionally, KIT mutations present distinct correlation with a number of different clinicopathologic features. KIT-mutated harboring melanomas are closely associated with older age, and acral, mucosal, or CSD sites but not with other histological parameters or tumor stage or sex. Intriguingly, no significant difference is recorded in the clinical association with KIT mutations between White populations and Asian populations although KIT mutation rate is lower in the latter one.

Upon treatment of melanoma subtypes, clinical efficacy in treating KIT-mutated melanoma has been evaluated with various small-molecular inhibitors of c-KIT, including imatinib, nilotinib, dasatinib, and sunitinib. Data collected from studies over 20 years has provided substantially critical insights into the therapeutic trials of these drugs and their success rate. However, in many cases, most patients eventually experience disease progression. One of possible explanation for this drug resistance is the frequent presence of brain and central nervous system metastases in advanced melanoma as the drug penetration is limited in these areas. With this being said, numerous additional investigational studies exploring c-KIT as a therapeutic target in combination therapy against melanoma. For instance, co-targeting c-KIT and its downstream pathways might be a plausible solution to control tumor progression. On the other hand, c-KIT inhibition showed its potential synergy with the immunological checkpoint blockade to develop antitumor effect. ${ }^{88,89}$ This is due to the ability of c-KIT inhibitors to enhance immune response such as increased T-cell activation and natural killer cell clonal expansion. ${ }^{90,91}$

\section{ACKNOWLEDGEMENTS}

This work was supported in part by a grant from the American Skin Association (to S.G.), the Melanoma Research Alliance (to H.T.) and by the generous donors to the Massachusetts General Hospital on behalf of melanoma research.

\section{AUTHOR CONTRIBUTIONS}

Conceptualization: Duc (Daniel) M. Pham and Hensin Tsao. Data 
curation: Duc (Daniel) M. Pham. Formal analysis: Duc (Daniel) M. Pham and Hensin Tsao. Funding acquisition: Hensin Tsao. Project administration: Hensin Tsao. Software: Duc (Daniel) M. Pham. Supervision: Hensin Tsao. Validation: all authors. Visualization: Duc (Daniel) M. Pham. Writing_original draft: Duc (Daniel) M. Pham. Writing - review \& editing: all authors. Approval of final manuscript: all authors.

\section{ORCID iDs}

Duc (Daniel) M. Pham

Samantha Guhan

Hensin Tsao https://orcid.org/0000-0002-7586-0510 https://orcid.org/0000-0002-5095-9733 https://orcid.org/0000-0002-2204-2071

\section{REFERENCES}

1. Besmer P, Murphy JE, George PC, Qiu FH, Bergold PJ, Lederman $\mathrm{L}$, et al. A new acute transforming feline retrovirus and relationship of its oncogene $\mathrm{v}$-kit with the protein kinase gene family. Nature 1986;320:415-21.

2. Yarden Y, Kuang WJ, Yang-Feng T, Coussens L, Munemitsu S, Dull TJ, et al. Human proto-oncogene c-kit: a new cell surface receptor tyrosine kinase for an unidentified ligand. EMBO J 1987;6:3341-51.

3. Antonescu CR. The GIST paradigm: lessons for other kinase-driven cancers. J Pathol 2011;223:251-61.

4. Lemmon MA, Ferguson KM. A new twist in the transmembrane signaling tool-kit. Cell 2007;130:213-5.

5. d'Auriol L, Mattei MG, Andre C, Galibert F. Localization of the human c-kit protooncogene on the q11-q12 region of chromosome 4. Hum Genet 1988;78:374-6.

6. Qiu FH, Ray P, Brown K, Barker PE, Jhanwar S, Ruddle FH, et al. Primary structure of c-kit: relationship with the CSF-1/PDGF receptor kinase family--oncogenic activation of v-kit involves deletion of extracellular domain and C terminus. EMBO J 1988;7:1003-11.

7. Crosier PS, Ricciardi ST, Hall LR, Vitas MR, Clark SC, Crosier KE. Expression of isoforms of the human receptor tyrosine kinase ckit in leukemic cell lines and acute myeloid leukemia. Blood 1993; 82:1151-8.

8. Reith AD, Ellis C, Lyman SD, Anderson DM, Williams DE, Bernstein A, et al. Signal transduction by normal isoforms and W mutant variants of the Kit receptor tyrosine kinase. EMBO J 1991;10: 2451-9.

9. Zhu WM, Dong WF, Minden M. Alternate splicing creates two forms of the human kit protein. Leuk Lymphoma 1994;12:441-7.

10. Chen SQ, Xiong AQ. The progress and implication of stem cell factor. Basic Med Sci Clin 2002;22:385-90.

11. Philo JS, Wen J, Wypych J, Schwartz MG, Mendiaz EA, Langley KE. Human stem cell factor dimer forms a complex with two molecules of the extracellular domain of its receptor, Kit. J Biol Chem 1996;271:6895-902.

12. Lemmon MA, Pinchasi D, Zhou M, Lax I, Schlessinger J. Kit receptor dimerization is driven by bivalent binding of stem cell factor. J Biol Chem 1997;272:6311-7.

13. Yuzawa S, Opatowsky Y, Zhang Z, Mandiyan V, Lax I, Schlessinger J. Structural basis for activation of the receptor tyrosine kinase KIT by stem cell factor. Cell 2007;130:323-34.

14. Hendriks RW. Drug discovery: new Btk inhibitor holds promise. Nat Chem Biol 2011;7:4-5.

15. Sansal I, Sellers WR. The biology and clinical relevance of the PTEN tumor suppressor pathway. J Clin Oncol 2004;22:2954-63.

16. Silva CM. Role of STATs as downstream signal transducers in Src family kinase-mediated tumorigenesis. Oncogene 2004;23:8017-23.
17. Summy JM, Gallick GE. Treatment for advanced tumors: SRC reclaims center stage. Clin Cancer Res 2006;12:1398-401.

18. Yasuda T, Kurosaki T. Regulation of lymphocyte fate by Ras/ERK signals. Cell Cycle 2008;7:3634-40.

19. Kitamura $Y$, Hirotab S. Kit as a human oncogenic tyrosine kinase. Cell Mol Life Sci 2004;61:2924-31.

20. Kuang D, Zhao X, Xiao G, Ni J, Feng Y, Wu R, et al. Stem cell factor/c-kit signaling mediated cardiac stem cell migration via activation of p38 MAPK. Basic Res Cardiol 2008;103:265-73.

21. Liang J, Wu YL, Chen BJ, Zhang W, Tanaka Y, Sugiyama H. The Ckit receptor-mediated signal transduction and tumor-related diseases. Int J Biol Sci 2013;9:435-43.

22. Stankov K, Popovic S, Mikov M. C-KIT signaling in cancer treatment. Curr Pharm Des 2014;20:2849-80.

23. Sun J, Pedersen M, Rönnstrand L. Gab2 is involved in differential phosphoinositide 3-kinase signaling by two splice forms of c-Kit. J Biol Chem 2008;283:27444-51.

24. Brunet A, Bonni A, Zigmond MJ, Lin MZ, Juo P, Hu LS, et al. Akt promotes cell survival by phosphorylating and inhibiting a Forkhead transcription factor. Cell 1999;96:857-68.

25. Datta SR, Dudek H, Tao X, Masters S, Fu H, Gotoh Y, et al. Akt phosphorylation of $\mathrm{BAD}$ couples survival signals to the cell-intrinsic death machinery. Cell 1997;91:231-41.

26. Dhandapani KM, Wade FM, Wakade C, Mahesh VB, Brann DW. Neuroprotection by stem cell factor in rat cortical neurons involves AKT and NFkappaB. J Neurochem 2005;95:9-19.

27. Yang E, Zha J, Jockel J, Boise LH, Thompson CB, Korsmeyer SJ. $\mathrm{Bad}$, a heterodimeric partner for Bcl-XL and Bcl-2, displaces Bax and promotes cell death. Cell 1995;80:285-91.

28. Jeon S, Kim NH, Kim JY, Lee AY. Stem cell factor induces ERM proteins phosphorylation through PI3K activation to mediate melanocyte proliferation and migration. Pigment Cell Melanoma Res 2009;22:77-85.

29. Han DC, Shen TL, Guan JL. The Grb7 family proteins: structure, interactions with other signaling molecules and potential cellular functions. Oncogene 2001;20:6315-21.

30. Thömmes K, Lennartsson J, Carlberg M, Rönnstrand L. Identification of Tyr-703 and Tyr-936 as the primary association sites for Grb2 and Grb7 in the c-Kit/stem cell factor receptor. Biochem J 1999;341(Pt 1):211-6.

31. Jahn T, Seipel P, Urschel S, Peschel C, Duyster J. Role for the adaptor protein Grb10 in the activation of Akt. Mol Cell Biol 2002;22: 979-91.

32. Sattler M, Salgia R, Shrikhande G, Verma S, Pisick E, Prasad KV, et al. Steel factor induces tyrosine phosphorylation of CRKL and binding of CRKL to a complex containing c-kit, phosphatidylinositol 3-kinase, and p120(CBL). J Biol Chem 1997;272:10248-53.

33. van Dijk TB, van Den Akker E, Amelsvoort MP, Mano H, Löwenberg B, von Lindern M. Stem cell factor induces phosphatidylinositol 3'-kinase-dependent Lyn/Tec/Dok-1 complex formation in hematopoietic cells. Blood 2000;96:3406-13.

34. Takaki S, Morita H, Tezuka Y, Takatsu K. Enhanced hematopoiesis by hematopoietic progenitor cells lacking intracellular adaptor protein, Lnk. J Exp Med 2002;195:151-60.

35. Drube S, Heink S, Walter S, Löhn T, Grusser M, Gerbaulet A, et al. The receptor tyrosine kinase c-Kit controls IL-33 receptor signaling in mast cells. Blood 2010;115:3899-906.

36. Wu H, Klingmüller U, Besmer P, Lodish HF. Interaction of the erythropoietin and stem-cell-factor receptors. Nature 1995;377:242-6.

37. Jahn T, Sindhu S, Gooch S, Seipel P, Lavori P, Leifheit E, et al. Direct interaction between Kit and the interleukin-7 receptor. Blood 2007;110:1840-7.

38. Anzai N, Lee Y, Youn BS, Fukuda S, Kim YJ, Mantel C, et al. C-kit 
associated with the transmembrane 4 superfamily proteins constitutes a functionally distinct subunit in human hematopoietic progenitors. Blood 2002;99:4413-21.

39. Corless CL, Fletcher JA, Heinrich MC. Biology of gastrointestinal stromal tumors. J Clin Oncol 2004;22:3813-25.

40. Maulik G, Bharti A, Khan E, Broderick RJ, Kijima T, Salgia R. Modulation of c-Kit/SCF pathway leads to alterations in topoisomerase-I activity in small cell lung cancer. J Environ Pathol Toxicol Oncol 2004;23:237-51.

41. Heinrich MC, Corless CL, Demetri GD, Blanke CD, von Mehren $\mathrm{M}$, Joensuu $\mathrm{H}$, et al. Kinase mutations and imatinib response in patients with metastatic gastrointestinal stromal tumor. J Clin Oncol 2003;21:4342-9.

42. Joensuu H, DeMatteo RP. The management of gastrointestinal stromal tumors: a model for targeted and multidisciplinary therapy of malignancy. Annu Rev Med 2012;63:247-58.

43. Berger MF, Hodis E, Heffernan TP, Deribe YL, Lawrence MS, Protopopov A, et al. Melanoma genome sequencing reveals frequent PREX2 mutations. Nature 2012;485:502-6.

44. Carvajal RD, Antonescu CR, Wolchok JD, Chapman PB, Roman RA, Teitcher J, et al. KIT as a therapeutic target in metastatic melanoma. JAMA 2011;305:2327-34.

45. Cerami E, Gao J, Dogrusoz U, Gross BE, Sumer SO, Aksoy BA, et al. The cBio cancer genomics portal: an open platform for exploring multidimensional cancer genomics data. Cancer Discov 2012;2: 401-4.

46. Curtin JA, Busam K, Pinkel D, Bastian BC. Somatic activation of KIT in distinct subtypes of melanoma. J Clin Oncol 2006;24:4340-6.

47. Gao J, Aksoy BA, Dogrusoz U, Dresdner G, Gross B, Sumer SO, et al. Integrative analysis of complex cancer genomics and clinical profiles using the cBioPortal. Sci Signal 2013;6:pl1.

48. Hodis E, Watson IR, Kryukov GV, Arold ST, Imielinski M, Theurillat JP, et al. A landscape of driver mutations in melanoma. Cell 2012; 150:251-63.

49. Hugo W, Zaretsky JM, Sun L, Song C, Moreno BH, Hu-Lieskovan S, et al. Genomic and transcriptomic features of response to antiPD-1 therapy in metastatic melanoma. Cell 2016;165:35-44.

50. Krauthammer M, Kong Y, Ha BH, Evans P, Bacchiocchi A, McCusker JP, et al. Exome sequencing identifies recurrent somatic RAC1 mutations in melanoma. Nat Genet 2012;44:1006-14.

51. Liang WS, Hendricks W, Kiefer J, Schmidt J, Sekar S, Carpten J, et al. Integrated genomic analyses reveal frequent TERT aberrations in acral melanoma. Genome Res 2017;27:524-32.

52. Shain AH, Garrido M, Botton T, Talevich E, Yeh I, Sanborn JZ, et al. Exome sequencing of desmoplastic melanoma identifies recurrent NFKBIE promoter mutations and diverse activating mutations in the MAPK pathway. Nat Genet 2015;47:1194-9.

53. Snyder A, Makarov V, Merghoub T, Yuan J, Zaretsky JM, Desrichard A, et al. Genetic basis for clinical response to CTLA-4 blockade in melanoma. N Engl J Med 2014;371:2189-99.

54. Van Allen EM, Miao D, Schilling B, Shukla SA, Blank C, Zimmer L, et al. Genomic correlates of response to CTLA- 4 blockade in metastatic melanoma. Science 2015;350:207-11.

55. Shtivelman E, Davies MQ, Hwu P, Yang J, Lotem M, Oren M, et al. Pathways and therapeutic targets in melanoma. Oncotarget 2014; 5:1701-52.

56. Carvajal RD, Lawrence DP, Weber JS, Gajewski TF, Gonzalez R, Lutzky J, et al. Phase II study of nilotinib in melanoma harboring KIT alterations following progression to prior KIT inhibition. Clin Cancer Res 2015;21:2289-96.

57. Gong HZ, Zheng HY, Li J. The clinical significance of KIT mutations in melanoma: a meta-analysis. Melanoma Res 2018;28:259-70.

58. Heinrich MC, Griffith DJ, Druker BJ, Wait CL, Ott KA, Zigler AJ.
Inhibition of c-kit receptor tyrosine kinase activity by STI 571, a selective tyrosine kinase inhibitor. Blood 2000;96:925-32.

59. Tuveson DA, Willis NA, Jacks T, Griffin JD, Singer S, Fletcher CD, et al. STI571 inactivation of the gastrointestinal stromal tumor cKIT oncoprotein: biological and clinical implications. Oncogene 2001;20:5054-8.

60. Guo J, Si L, Kong Y, Flaherty KT, Xu X, Zhu Y, et al. Phase II, openlabel, single-arm trial of imatinib mesylate in patients with metastatic melanoma harboring c-Kit mutation or amplification. J Clin Oncol 2011;29:2904-9.

61. Hodi FS, Corless CL, Giobbie-Hurder A, Fletcher JA, Zhu M, Marino-Enriquez A, et al. Imatinib for melanomas harboring mutationally activated or amplified KIT arising on mucosal, acral, and chronically sun-damaged skin. J Clin Oncol 2013;31:3182-90.

62. Wei X, Mao L, Chi Z, Sheng X, Cui C, Kong Y, et al. Efficacy evaluation of imatinib for the treatment of melanoma: evidence from a retrospective study. Oncol Res 2019;27:495-501.

63. Cullinane C, Natoli A, Hui Y, Conus N, Jackson S, Brüggen J, et al. Preclinical evaluation of nilotinib efficacy in an imatinib-resistant KIT-driven tumor model. Mol Cancer Ther 2010;9:1461-8.

64. Cho JH, Kim KM, Kwon M, Kim JH, Lee J. Nilotinib in patients with metastatic melanoma harboring KIT gene aberration. Invest New Drugs 2012;30:2008-14.

65. Delyon J, Chevret S, Jouary T, Dalac S, Dalle S, Guillot B, et al. STAT3 mediates nilotinib response in KIT-altered melanoma: a phase II multicenter trial of the French Skin Cancer Network. J Invest Dermatol 2018;138:58-67.

66. Guo J, Carvajal RD, Dummer R, Hauschild A, Daud A, Bastian BC, et al. Efficacy and safety of nilotinib in patients with KIT-mutated metastatic or inoperable melanoma: final results from the global, single-arm, phase II TEAM trial. Ann Oncol 2017;28:1380-7.

67. Lee SJ, Kim TM, Kim YJ, Jang KT, Lee HJ, Lee SN, et al. Phase II trial of nilotinib in patients with metastatic malignant melanoma harboring KIT gene aberration: a multicenter trial of Korean Cancer Study Group (UN10-06). Oncologist 2015;20:1312-9.

68. Lombardo LJ, Lee FY, Chen P, Norris D, Barrish JC, Behnia K, et al. Discovery of N-(2-chloro-6-methyl- phenyl)-2-(6-(4-(2-hydroxyethyl)- piperazin-1-yl)-2-methylpyrimidin-4- ylamino)thiazole5-carboxamide (BMS-354825), a dual Src/Abl kinase inhibitor with potent antitumor activity in preclinical assays. J Med Chem 2004;47:6658-61.

69. Kalinsky K, Lee S, Rubin KM, Lawrence DP, Iafrarte AJ, Borger DR, et al. A phase 2 trial of dasatinib in patients with locally advanced or stage IV mucosal, acral, or vulvovaginal melanoma: a trial of the ECOG-ACRIN Cancer Research Group (E2607). Cancer 2017;123: 2688-97.

70. Kluger HM, Dudek AZ, McCann C, Ritacco J, Southard N, Jilaveanu LB, et al. A phase 2 trial of dasatinib in advanced melanoma. Cancer 2011;117:2202-8.

71. Decoster L, Vande Broek I, Neyns B, Majois F, Baurain JF, Rottey S, et al. Biomarker analysis in a phase II study of sunitinib in patients with advanced melanoma. Anticancer Res 2015;35:6893-9.

72. Minor DR, Kashani-Sabet M, Garrido M, O'Day SJ, Hamid O, Bastian BC. Sunitinib therapy for melanoma patients with KIT mutations. Clin Cancer Res 2012;18:1457-63.

73. Prosvicova J, Lukesova S, Kopecky J, Grim J, Papik Z, Kolarova R, et al. Rapid and clinically significant response to masitinib in the treatment of mucosal primary esophageal melanoma with somatic KIT exon 11 mutation involving brain metastases: a case report. Biomed Pap Med Fac Univ Palacky Olomouc Czech Repub 2015;159:695-7.

74. Quintás-Cardama A, Lazar AJ, Woodman SE, Kim K, Ross M, Hwu P. Complete response of stage IV anal mucosal melanoma 
expressing KIT Val560Asp to the multikinase inhibitor sorafenib. Nat Clin Pract Oncol 2008;5:737-40.

75. Chen Z, Pan X, Yao Y, Yan F, Chen L, Huang R, et al. Epigenetic regulation of cardiac progenitor cells marker c-kit by stromal cell derived factor- $1 \alpha$. PLoS One 2013;8:e69134.

76. Lyberg K, Ali HA, Grootens J, Kjellander M, Tirfing M, Arock M, et al. Histone deacetylase inhibitor SAHA mediates mast cell death and epigenetic silencing of constitutively active D816V KIT in systemic mastocytosis. Oncotarget 2017;8:9647-59.

77. Janostiak R, Vyas M, Cicek AF, Wajapeyee N, Harigopal M. Loss of c-KIT expression in breast cancer correlates with malignant transformation of breast epithelium and is mediated by KIT gene promoter DNA hypermethylation. Exp Mol Pathol 2018;105:41-9.

78. Chao WR, Lin WL, Chen CK, Han LM, Lin JC, Han CP. Unusual cKIT+ squamous cell carcinoma of the uterine cervix showing paradoxical hypermethylation of the c-KIT proto-oncogene. Eur J Obstet Gynecol Reprod Biol 2015; 184:130-1.

79. Chang SW, Chao WR, Ruan A, Wang PH, Lin JC, Han CP. A promising hypothesis of c-KIT methylation/ expression paradox in c-KIT (+) squamous cell carcinoma of uterine cervix ----- CTCF transcriptional repressor regulates c-KIT proto-oncogene expression. Diagn Pathol 2015;10:207.

80. Syed SA, Hayashi Y, Modak MV, Tice J, Nagy RA, McGehee CD, et al. 240 Epigenetic regulation of kit expression in murine $\mathrm{Kit}^{\mathrm{Low}}$ interstitial cell of cajal stem cells (ICC-SC) and Kit ${ }^{\mathrm{Low}}$ gastrointestinal stromal tumor (GIST) cells by polycomb group (PcG) repressive complexes (PRC). Gastroenterology 2013;144(5 Suppl 1):S-52.

81. Dahl C, Abildgaard C, Riber-Hansen R, Steiniche T, Lade-Keller J, Guldberg P. KIT is a frequent target for epigenetic silencing in cutaneous melanoma. J Invest Dermatol 2015;135:516-24.

82. Isabel Zhu Y, Fitzpatrick JE. Expression of c-kit (CD117) in Spitz nevus and malignant melanoma. J Cutan Pathol 2006;33:33-7.
83. Montone KT, van Belle P, Elenitsas R, Elder DE. Proto-oncogene c-kit expression in malignant melanoma: protein loss with tumor progression. Mod Pathol 1997;10:939-44.

84. Shen SS, Zhang PS, Eton O, Prieto VG. Analysis of protein tyrosine kinase expression in melanocytic lesions by tissue array. J Cutan Pathol 2003;30:539-47.

85. Ecsedi S, Hernandez-Vargas H, Lima SC, Vizkeleti L, Toth R, Lazar $\mathrm{V}$, et al. DNA methylation characteristics of primary melanomas with distinct biological behaviour. PLoS One 2014;9:e96612.

86. Felicetti F, Errico MC, Bottero L, Segnalini P, Stoppacciaro A, Biffoni $\mathrm{M}$, et al. The promyelocytic leukemia zinc finger-microRNA-221/-222 pathway controls melanoma progression through multiple oncogenic mechanisms. Cancer Res 2008;68:2745-54.

87. Bell RE, Golan T, Sheinboim D, Malcov H, Amar D, Salamon A, et al. Enhancer methylation dynamics contribute to cancer plasticity and patient mortality. Genome Res 2016;26:601-11.

88. Balachandran VP, Cavnar MJ, Zeng S, Bamboat ZM, Ocuin LM, Obaid $\mathrm{H}$, et al. Imatinib potentiates antitumor $\mathrm{T}$ cell responses in gastrointestinal stromal tumor through the inhibition of Ido. Nat Med 2011;17:1094-100.

89. Seifert AM, Zeng S, Zhang JQ, Kim TS, Cohen NA, Beckman MJ, et al. PD-1/PD-L1 blockade enhances T-cell activity and antitumor efficacy of imatinib in gastrointestinal stromal tumors. Clin Cancer Res 2017;23:454-65.

90. Lee KC, Ouwehand I, Giannini AL, Thomas NS, Dibb NJ, Bijlmakers MJ. Lck is a key target of imatinib and dasatinib in T-cell activation. Leukemia 2010;24:896-900.

91. Kreutzman A, Juvonen V, Kairisto V, Ekblom M, Stenke L, Seggewiss $\mathrm{R}$, et al. Mono/oligoclonal $\mathrm{T}$ and NK cells are common in chronic myeloid leukemia patients at diagnosis and expand during dasatinib therapy. Blood 2010;116:772-82. 